\title{
The flux rate of $\mathrm{Ca}^{2+}$ into embryo can be used to evaluate the vigour level of maize seeds
}

\author{
P. Zhu", X. Song", Y. Mao, Y. Li*, C. Zhang* \\ State Key Laboratory of Crop Biology, Agronomy College, Shandong Agricultural University, Tai'an 271018, China
}

Corresponding Authors: Y. Li, yanli@sdau.edu.cn; C. Zhang, cqzhang@sdau.edu.cn

Received: 14 November 2019 / Accepted: 16 April 2020 / Published: 10 June 2020

(c) 2020 Codon Publications

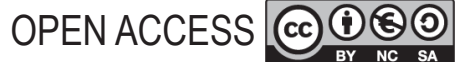

RESEARCH ARTICLE

\begin{abstract}
Seed vigour is an important trait and is often used to evaluate seed quality. A rapid and accurate evaluation of seed vigour is very important for agricultural production. $\mathrm{Ca}^{2+}$ is an important secondary messenger in plants, responding to various biotic and abiotic stimuli by $\mathrm{Ca}^{2+}$ flux into cytoplasm. To the best of our knowledge, however, no report has been published about seed vigour and $\mathrm{Ca}^{2+}$ influx. In this study, we used two hybrid maize (Zea mays L.) lines and their corresponding female parent lines as materials, and performed ageing and 'ageing + priming' treatments to obtain seeds with different vigour levels. After seeds were imbibed for $24 \mathrm{~h}$, the intact seeds or embryos were used as materials for determining the $\mathrm{Ca}^{2+}$ influx rate using non-invasive micro-test technique (NMT). Results showed that, with the intact embryos as materials, the $\mathrm{Ca}^{2+}$ influx rate showed higher stability and higher values. Correlation analysis indicated that there was a significant, positive linear correlation between the shoot dry weight vigour index and $\mathrm{Ca}^{2+}$ flux rate into embryo. The results demonstrated that the $\mathrm{Ca}^{2+}$ influx rate can be used to evaluate the vigour levels of maize seeds.
\end{abstract}

Keywords: correlation analysis, non-invasive micro-test technique, seed vigour, Zea mays

\section{Introduction}

Seed vigour is an important trait for evaluating seed quality. It can reflect the performance of seedling emergence in the field. Seeds with high vigour exhibit rapid and uniform seedling emergence and high stress resistance (Finch-Savage and Bassel, 2016). Low-vigour seeds can germinate under favourable conditions, but under stress conditions, seedling emergence is not uniform, or even no seedlings emerge, which severely impacts agricultural production (Finch-Savage and Bassel, 2016).

Seed vigour is a complex agronomic trait controlled by multiple genes. Han et al. (2014) identified 23 candidate genes in maize that were correlated with seed vigour.
Thus, an accurate evaluation of the level of seed vigour is a difficult task. There are currently dozens of methods for measuring seed vigour that can be generally divided into direct and indirect methods (Hampton and Tekrony, 1995). The direct method is to simulate various field conditions in the laboratory and to measure the seedling growth rate and seedling robustness, such as the low temperature test, the brick grit test and the accelerated ageing test (Hampton and Tekrony, 1995). The direct methods are often time- and labour-consuming, with low efficiency. Indirect methods measure the physiological and biochemical parameters related to seed vigour in the laboratory, such as leachate conductivity (ISTA, 2014) and oxygen consumption during imbibition (Bello and Bradford, 2016), to evaluate the level of seed vigour.

${ }^{*} P$. Zhu and X. Song contributed equally to this work. 
$\mathrm{Ca}^{2+}$ is an important secondary messenger in plants, responding to various biotic and abiotic stimuli including pathogens, cold, heat, salt and drought stresses (Sanders et al., 1999). Calcium is stored in plants in organelles such as the vacuole, endoplasmic reticulum, mitochondria and chloroplasts, as well as in the apoplastic cell wall bound to the pectin (Stael et al., 2012). When plants are stimulated by environmental stress, $\mathrm{Ca}^{2+}$ flux occurs, with $\mathrm{Ca}^{2+}$ moving from the calcium stores to the cytoplasm, which causes the concentration of cytosolic-free $\mathrm{Ca}^{2+}$ to increase rapidly. The $\mathrm{Ca}^{2+}$ then binds to $\mathrm{Ca}^{2+}$ sensors, such as calmodulin, CaM-like proteins, calcium-dependent protein kinases and calcineurin B-like proteins, to transmit the stimulus signals (Bickerton and Pittman, 2012).

To the best of our knowledge, however, there has been no report on the relationship between the $\mathrm{Ca}^{2+}$ flux rate and seed vigour, although some studies have shown that $\mathrm{Ca}^{2+}$ plays important roles in promoting seed germination and increasing stress resistance of seedling. Singh et al. (2017) found that the early axis growth of germinating Vigna radiata seeds was under the control of auxin and cytosolic $\mathrm{Ca}^{2+}$. Recently, Verma et al. (2019) further showed that the apoplastic calcium store is the main source of $\mathrm{Ca}^{2+}$ needed during germination and the initial stage of seedling establishment in $V$. radiata. In addition, the calmodulin-like protein CML39 is involved in Arabidopsis seed germination (Midhat et al., 2018). Seed priming with $\mathrm{CaCl}_{2}$ solution significantly reduced the chilling damage (Farooq et al., 2008). The addition of exogenous $\mathrm{CaCl}_{2}$ reduced the effect of salt stress on seed germination in Phragmites karka and Festuca ovina (Salahshoor and Kazemi, 2016; Zehra et al., 2012). Glutamate Receptor AtGLR3.4, which mediates $\mathrm{Ca}^{2+}$ influx, is involved in the regulation of seed germination in Arabidopsis under salt stress (Cheng et al., 2018). In addition, exogenous glutamate treatment increased the resistance in maize seedlings to heat stress via glutamate-receptor-mediated $\mathrm{Ca}^{2+}$ signalling (Li et al., 2019).

Non-invasive micro-test technique (NMT) is a tool for studying the physiological functions in living cells or tissues. This technology uses selective electrodes and detects the three-dimensional flux rate of molecules or ions across the membrane of living organisms while ensuring the integrity of tested samples, at a testing condition similar to the actual physiological environment (McLamore and Porterfield, 2011). It has been widely applied in the field of plant physiology, including seed physiology. Xin et al. (2013) detected seed viability of soybean, wheat and oilseed rape using oxygen influx by NMT. Li et al. (2014) measured the flux rate of $\mathrm{O}_{2}$ and $\mathrm{H}_{2} \mathrm{O}_{2}$ in the non-coated seeds of Caragana korshinskii and proposed that the $\mathrm{O}_{2}$ influx rate can be used for the evaluation of seed vigour. Using NMT, we established the correlation between the flux rate of $\mathrm{Ca}^{2+}$ into embryo and the vigour of maize seeds. We found that the flux rate of $\mathrm{Ca}^{2+}$ into embryo can be used to evaluate the seed vigour of maize.

\section{Materials and methods}

\section{Plant materials}

The seeds of four maize materials, hybrid XY335 and its female parent PH6WC, and hybrid ZD958 and its female parent Z58, bought from the market, were used in this study. The hybrids XY335 and ZD958 have been the largest cultivars in China over the past decade.

\section{Ageing and priming treatments}

Seeds were first placed in a net bag and were evenly laid out in an artificial ageing chamber at $45{ }^{\circ} \mathrm{C}$ and $90 \%$ relative humidity (RH), for $96 \mathrm{~h}$ for ageing treatment, and then the seeds were air-dried. Some of the aged seeds were then placed between sheets of Whatman No. 1 filter paper soaked with deionised water at $25^{\circ} \mathrm{C}$ for $10 \mathrm{~h}$. Then, water on the seed surface was removed, and the seeds were air-dried again, as 'ageing + priming' treated seeds. Seeds without any treatment were used as control (CK). The seeds were then sealed in bags for further use.

\section{Determination of vigour index}

In accordance with international standards for seed testing, a standard germination test was conducted. Sand with $0.05-0.8 \mathrm{~mm}$ diameter was used to prepare the sand bed for the seed germination test. The water content of the sand bed was $60 \%$ of its saturated water content. In each of the three replicates, 50 seeds were placed in a growth chamber at $25^{\circ} \mathrm{C}$, with a $16 \mathrm{~h}$ light $/ 8 \mathrm{~h}$ dark photoperiod. The number of normal seedlings to emerge was recorded daily from the third day to the seventh day. On the seventh day, seedlings were taken out of the germination box and washed, and then residual seed tissue was removed. The roots and shoots of the seedlings were separated, dried and weighed. The germination index (GI), plant dry weight vigour index (PDWVI), shoot dry weight vigour index (SDWVI) and root dry weight vigour index (RDWVI) were calculated using the following equations:

$$
\begin{aligned}
& G I=\sum(G t / D t), \\
& \mathrm{VI}=G I \times S,
\end{aligned}
$$

where $G t$ is the number of germinating seeds on day $\mathrm{t}$, $D t$ is the number of germination days and $S$ is plant dry weight (for PDWVI, g), shoot dry weight (for SDWVI, g) or root dry weight (for RDWVI, g). 


\section{Determination of $\mathrm{Ca}^{2+}$ flux rate}

Maize seeds were placed between sheets of Whatman No. 1 filter paper soaked with de-ionised water, and imbibed at $25^{\circ} \mathrm{C}$ for $24 \mathrm{~h}$. Then, the intact seed or embryo (obtained by carefully removing the endosperm and the pericarp and testa with a scalpel) was fixed in a Petri dish as shown in Figure 1.

$\mathrm{Ca}^{2+}$ flux rate was determined according to Jing et al. (2019) with minor modification. A glass microelectrode was filled with filling solution $\left(100 \mathrm{mM} \mathrm{CaCl}_{2}\right)$ from the back end to produce a liquid column of about 10 $\mathrm{mm}$. Then the filling solution was pressed to the tip of the electrode by using air pressure. And then $\mathrm{Ca}^{2+}$ liquid ion exchange agent (LIX) (XY-SJ-Ca, Younger USA, Amherst, MA, USA) was inhaled at the tip, with a length of about 40-50 $\mu \mathrm{m}$. The $\mathrm{Ag} / \mathrm{AgCl}$ wire is inserted from the back end of the electrode to bring it into contact with the electrolyte solution. Only electrodes with Nernstian slopes between 24 and $26 \mathrm{mV} /$ decade were used. Then, $\mathrm{Ca}^{2+}$ measuring buffer, containing $\mathrm{KCl}(0.1 \mathrm{mM}), \mathrm{CaCl}_{2}$
(0.1 mM), $\mathrm{MgCl}_{2}(0.1 \mathrm{mM}), \mathrm{NaCl}(0.5 \mathrm{mM}), \mathrm{Na}_{2} \mathrm{SO}_{4}(0.2$ $\mathrm{mM})$ and MES (0.3 mM), was added into the petri dish, and stabilised for 5-10 min. After that, the petri dish was placed on the platform of the NMT system (NMT100SIM-YG, YoungerUSA, LLC, Amherst, MA, USA). And then, the microelectrode was gradually brought closer to the sample through the adjustment of the computer movement module, until the distance between the electrode tip and the sample was maintained at 2-5 $\mu \mathrm{m}$. Each sample was continuously measured for $10 \mathrm{~min}$, with at least 10 biological replicates.

$\mathrm{Ca}^{2+}$ fluxes were calculated by Fick's law of diffusion:

$\mathrm{J}_{0}=-[\mathrm{D} \times(\mathrm{dC} / \mathrm{dX})]$

where $\mathrm{J}_{0}$ represents the net $\mathrm{Ca}^{2+}$ flux $\left(\mu \mathrm{mol} \mathrm{cm}{ }^{-2} \mathrm{~s}^{-1}\right)$, $D$ is the self-diffusion coefficient for $\mathrm{Ca}^{2+}\left(\mathrm{cm}^{2} \mathrm{~s}^{-1}\right), \mathrm{dC}$ is the difference value of $\mathrm{Ca}^{2+}$ concentrations between the two positions and $\mathrm{dX}$ is the distance between the two positions $(10 \mu \mathrm{m}$ in our expriment).
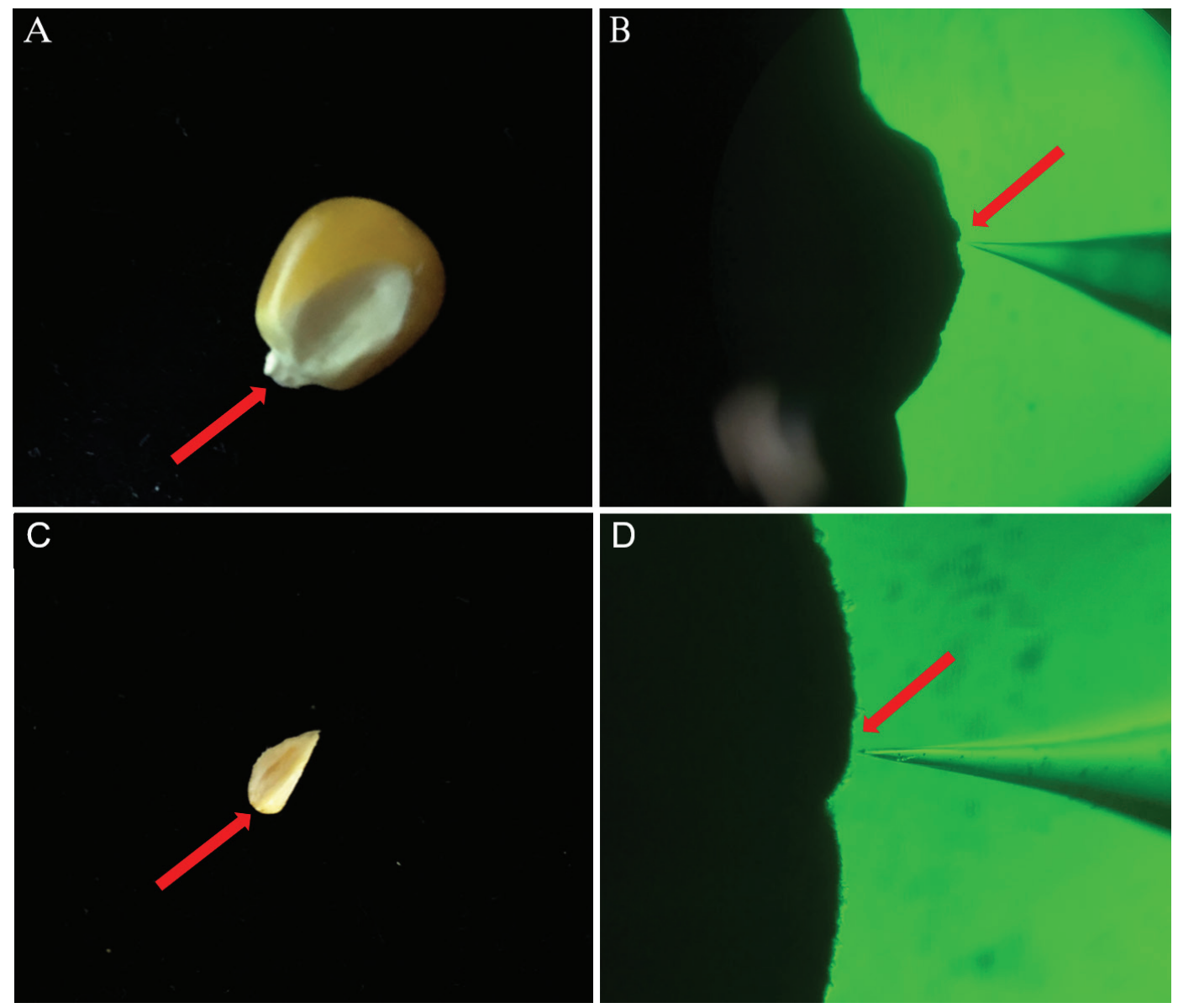

Figure 1. The positions (indicated by arrows) on the (A, B) entire maize seeds and (C, D) the embryos used for non-invasive micro-test technique detection under $(A, C)$ normal visual field and $(B, D)$ the microscope visual field. 


\section{Statistical analysis}

Each measurement was taken from at least 10 individual seeds. The results are herein expressed as means \pm SD. Data were tested for significance using one-way ANOVA with the IBM SPSS Statistics 19.0 software (SPSS, Chicago, IL, USA).

\section{Results}

\section{Embryo of maize seed is the ideal material for determining the $\mathrm{Ca}^{2+}$ flux rate using NMT}

NMT is a highly sensitive technology, so the position of the seed used for detection affects the results (Xin et al., 2013). Xin et al. (2013) found that the site of centre of the wheat seed embryo during imbibition showed the highest

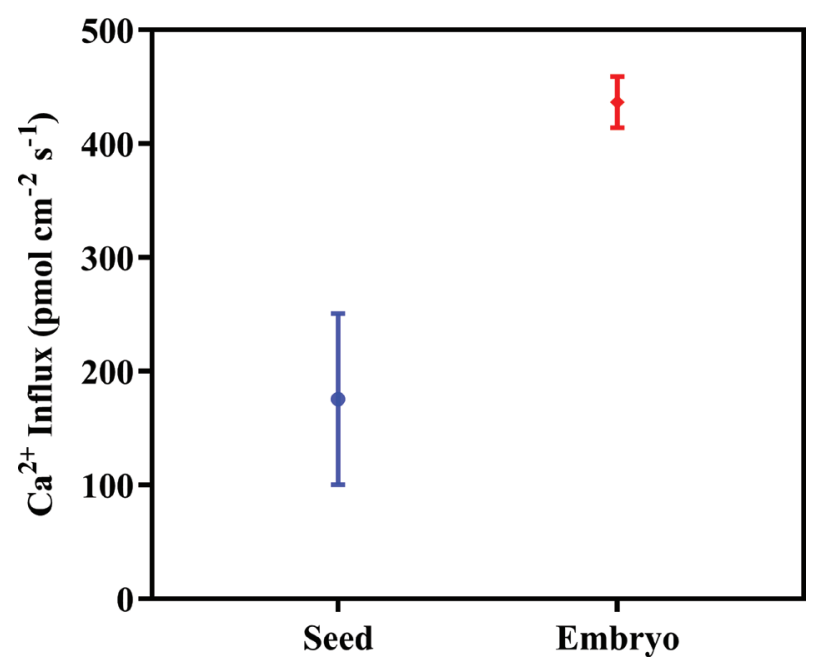

Figure 2. The difference in the $\mathrm{Ca}^{2+}$ influx rate between the entire seed and embryo used as materials. Data represent the means \pm SD of 12 biological replicates.
$\mathrm{O}_{2}$ influx, suggesting that the embryo as the living tissue, showed the most active respiration and metabolism during seed imbibition. In the present study, we first tested the intact seeds imbibed for $24 \mathrm{~h}$ (Figure $1 \mathrm{~A}$ and $\mathrm{B}$ ) and found that the direction of $\mathrm{Ca}^{2+}$ flow was influx, and that the flux rate was unstable (Figure 2). In the mature maize seeds, embryo is the living tissue, and the covering tissues, the starchy endosperm and the compact pericarp and testa are dead (Domínguez and Cejudo, 2014), this is likely to affect $\mathrm{Ca}^{2+}$ influx. Therefore, we used the intact embryo for NMT detection (Figure $1 \mathrm{C}$ and D). The results showed that the direction of $\mathrm{Ca}^{2+}$ flow in intact embryo was the same as in the entire maize seeds, and that compared with those of the entire maize seeds, data stability was better and the value larger (Figure 2). As a result, the intact embryo isolated from maize seeds imbibed for $24 \mathrm{~h}$ was further used for NMT detection in the present study.

\section{The flux rate of $\mathrm{Ca}^{2+}$ into embryo exhibited a significantly positive linear correlation with maize seed vigour}

Using intact embryo as materials, we measured the $\mathrm{Ca}^{2+}$ influx rate of hybrid maize XY335 and ZD958 and their female parents PH6WC and Z58 using NMT. Results are shown in Figure 3. Different maize varieties exhibited clear differences in the $\mathrm{Ca}^{2+}$ influx rate. Among them, $\mathrm{XY} 335$ and ZD958 showed a higher $\mathrm{Ca}^{2+}$ influx rate, followed by PH6WC. Z58 exhibited the lowest $\mathrm{Ca}^{2+}$ influx rate among the four maize varieties (Figure 3).

To determine the correlation between the flux rate of $\mathrm{Ca}^{2+}$ into embryo of different maize varieties and the seed vigour, we determined PDWVI, SDWVI and RDWVI, and the average $\mathrm{Ca}^{2+}$ influx rate in $10 \mathrm{~min}$ (Figure 4).

For the average $\mathrm{Ca}^{2+}$ influx rate among the four varieties, XY335 and ZD958 had the highest values without significant difference between them. PH6WC had a

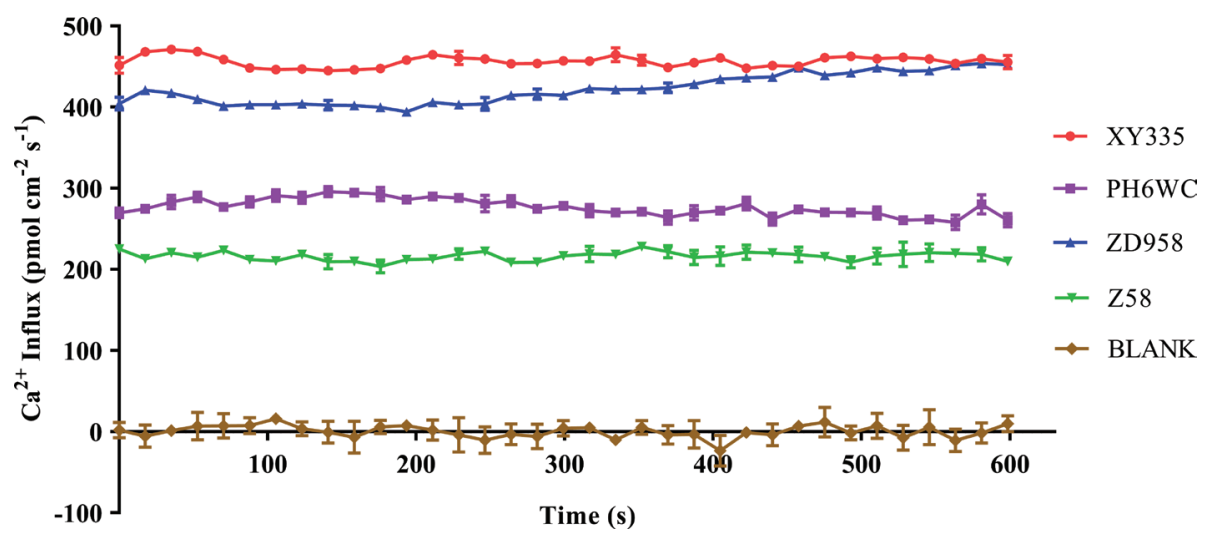

Figure 3. The dynamics of the flux rate of $\mathrm{Ca}^{2+}$ into one embryo of the four different maize varieties (XY335, PH6WC, ZD958 and Z58) for $600 \mathrm{~s}$. The testing solution without seeds was used as BLANK. 

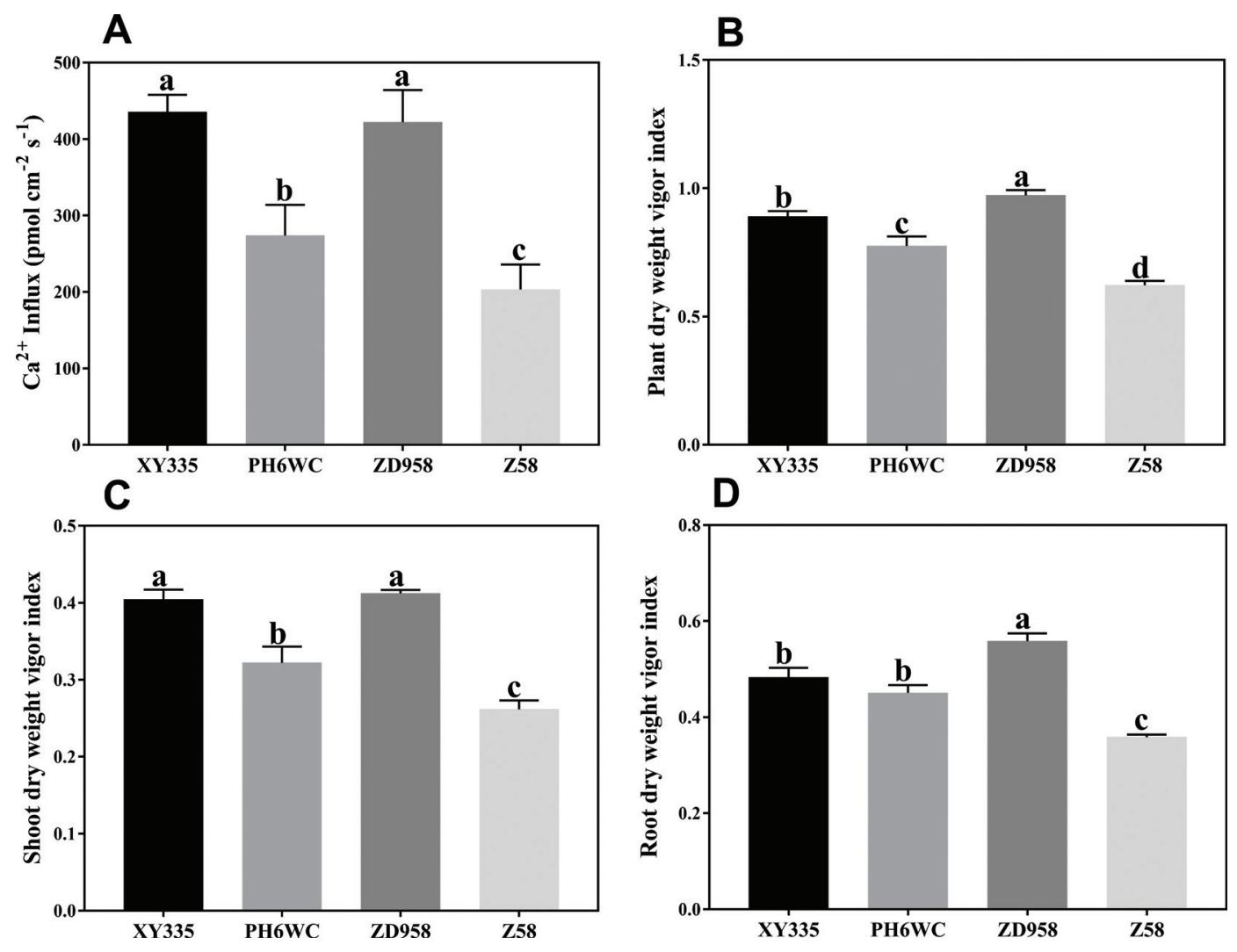

Figure 4. The average flux rate of $\mathrm{Ca}^{2+}$ into embryo (A) and the plant dry weight vigour index (B), shoot dry weight vigour index (C) and root dry weight vigour index (D) of the four different maize varieties (XY335, PH6WC, ZD958 and Z58). Data represent the means \pm SD of 10 biological replicates (A) or four biological replicates (B-D). An ANOVA test followed by a rank test was performed. Different letters are used to indicate means that are significantly different $(P<0.05)$.

significantly lower $(P<0.05) \mathrm{Ca}^{2+}$ influx rate than XY335 and ZD958, while Z58 showed the lowest value; the difference between Z58 and PH6WC was significant $(P<$ 0.05, Figure 4A). On comparing PDWVI, SDWVI and RDWVI, we found that the differences in SDWVI of the four maize varieties showed the closest correlation with the differences in the average $\mathrm{Ca}^{2+}$ influx rate (Figure 4). SDWVI of XY335 and ZD958 showed the highest values with no significant difference between them. PH6WC had a significantly lower value than XY335 and ZD958. Z58 had the lowest SDWVI value, significantly different from that of PH6WC (Figure 4C).

To further test the correlation between the flux rate of $\mathrm{Ca}^{2+}$ into the embryo and SDWVI of the maize seeds, we performed a 96 -h artificial ageing treatment at $45^{\circ} \mathrm{C}$ and RH 90\% on XY335 and ZD958, followed by a priming treatment. Then, the $\mathrm{Ca}^{2+}$ flux rate into the embryo and the SDWVI of the maize seeds were measured. Results showed that the control (CK) had the highest values of $\mathrm{Ca}^{2+}$ influx rate and SDWVI, followed by the seeds from the 'ageing + priming' treatment (SP), with the seeds from the ageing treatment (SA) being the lowest (Figure 5).
Correlation analysis was performed using SPSS on 12 groups of data concerning the embryo $\mathrm{Ca}^{2+}$ flux rate and SDWVI. The $\mathrm{Ca}^{2+}$ flux rate into the embryo was set as the independent variable, and SDWVI was set as the dependent variable. Results showed that the embryo $\mathrm{Ca}^{2+}$ flux rate exhibited a highly significant, positive correlation with SDWVI $(P<0.0001)$. Moreover, SDWVI and the embryo $\mathrm{Ca}^{2+}$ flux rate fit the linear regression equation: $\mathrm{Y}=0.0007227 \mathrm{X}+0.1155\left(\mathrm{R}^{2}=0.8452\right.$; Y: SDWVI, X: flux rate of $\mathrm{Ca}^{2+}$ into embryo; Figure 6).

\section{Discussion}

Seed vigour is an important trait for evaluating seed quality and is more sensitive than the seed germination rate (Finch-Savage and Bassel, 2016). A rapid and accurate evaluation of seed vigour is crucial for agricultural practice. In this study, we used NMT to investigate the correlation between the $\mathrm{Ca}^{2+}$ influx rate into the embryo and the maize seed vigour. We found that the embryo $\mathrm{Ca}^{2+}$ influx rate exhibited a linear relationship with SDWVI of maize seeds. Therefore, the flux rate of $\mathrm{Ca}^{2+}$ into the embryo can be used to evaluate the seed vigour of maize. 

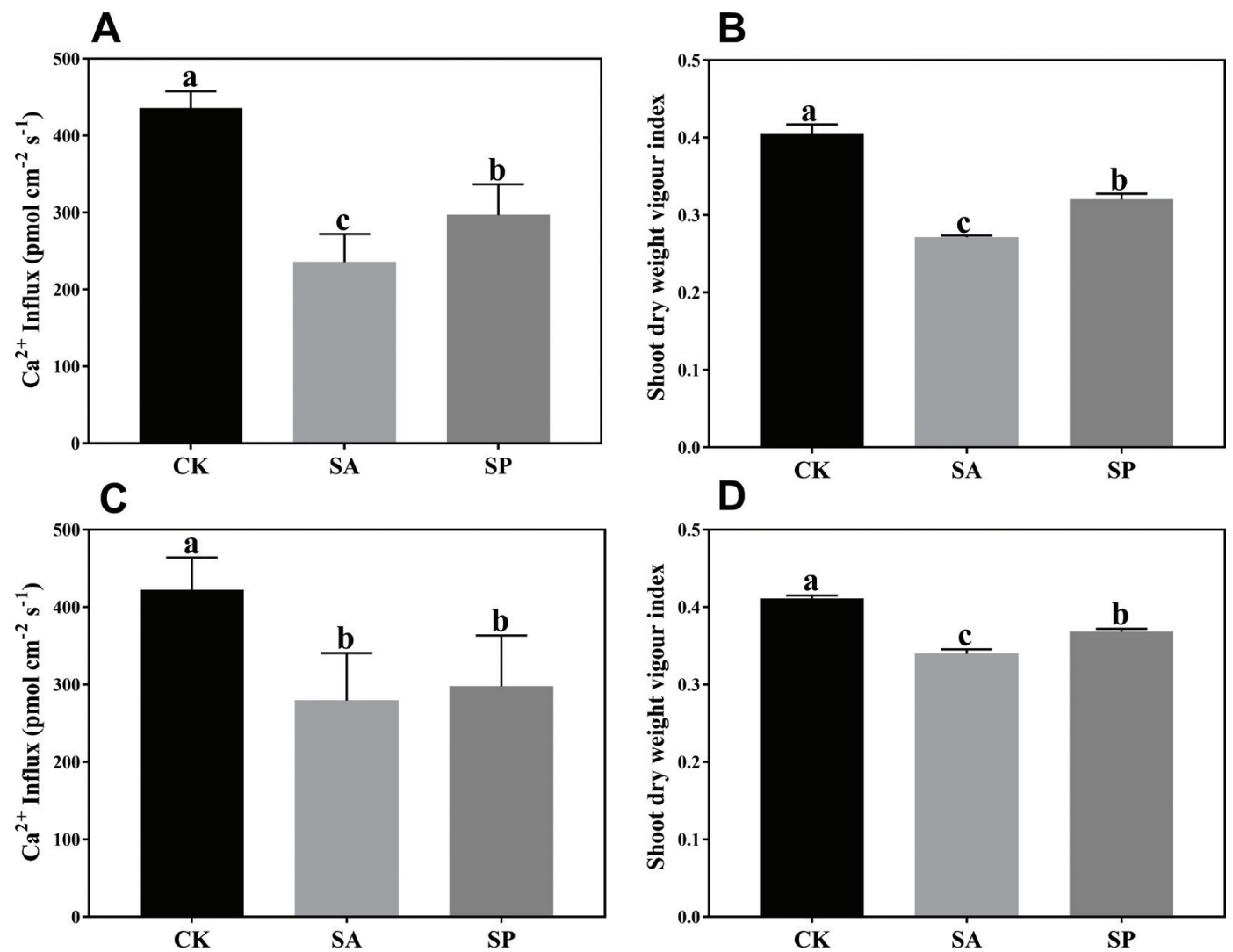

Figure 5. Seed vigour and the flux rate of $\mathrm{Ca}^{2+}$ into the embryo in different treatments. (A) $\mathrm{Ca}^{2+}$ influx rate of XY335 under different treatments; (B) Shoot dry weight vigour index (SDWVI) in XY335 under different treatments; (C) $\mathrm{Ca}^{2+}$ influx rate of ZD958 under different treatments; (D) SDWVI in ZD958 under different treatments. CK, no treatment applied; SA, artificial ageing treatment; SP, artificial 'ageing + priming' treatment. Data represent the means \pm SD of 10 biological replicates $(A, C)$ or four biological replicates $(B, D)$. An ANOVA test followed by a rank test was performed. Different letters are used to indicate means that are significantly different $(P<0.05)$.

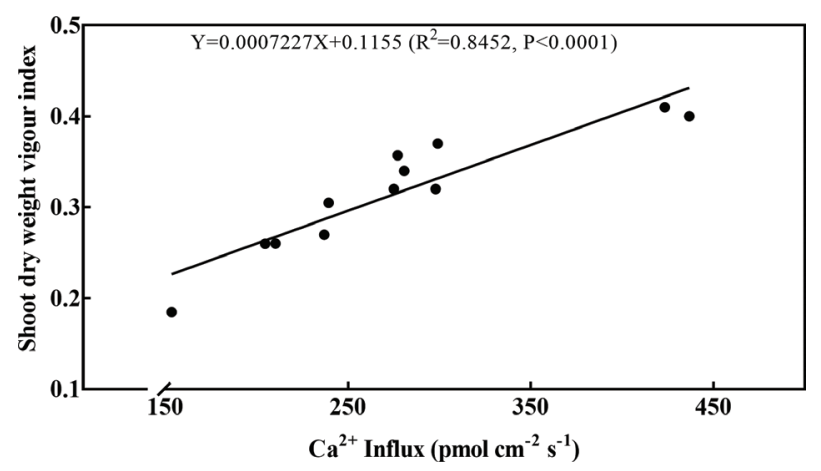

Figure 6. Shoot dry weight vigour index of maize seeds exhibited a significant, positive linear relationship with $\mathrm{Ca}^{2+}$ flux rate into the embryo.

$\mathrm{Ca}^{2+}$ is an important intracellular secondary messenger. Studies have shown that $\mathrm{Ca}^{2+}$ plays important roles in seed germination. In rice seeds, $\mathrm{Ca}^{2+}$ is involved in the synthesis of $\alpha$-amylase induced by gibberellins (Kaneko et al., 2002). $\mathrm{Ca}^{2+}$ activates a protease in germinating
V. radiata seeds (Khan et al., 2010) and regulates early axis growth during seed germination in $V$. radiata (Singh et al., 2017). The calmodulin-like protein, CML39, is involved in seed germination in Arabidopsis. Cml39 mutants exhibit a more rapid germination and decreased sensitivity to ABA or GA (Midhat et al., 2018). This raised the question of whether the $\mathrm{Ca}^{2+}$ involved in seed germination from cytosolic or apoplastic calcium storage. Singh et al. (2017) and Verma et al. (2019) reported that the $\mathrm{Ca}^{2+}$ required for the early stage of seed germination was from apoplastic calcium storage. This is consistent with the results in this study, where we found that $\mathrm{Ca}^{2+}$ exhibited influx into intact embryo. Seeds with high vigour germinate faster and exhibit stronger stress resistance. Previous studies have shown that $\mathrm{Ca}^{2+}$ indeed is involved in plant stress responses. The addition of exogenous $\mathrm{CaCl}_{2}$ reduced the effect of salt stress on seed germination in P. karka and F. ovina (Salahshoor and Kazemi, 2016; Zehra et al., 2012). The glutamate receptor AtGLR3.4 that mediates $\mathrm{Ca}^{2+}$ influx is involved in the regulation of seed germination in Arabidopsis under 
salt stress (Cheng et al., 2018). Also, exogenous glutamate treatment can increase the heat stress resistance in young maize seedlings via glutamate-receptor-mediated $\mathrm{Ca}^{2+}$ signalling (Li et al., 2019).

Root:shoot ratio biomass partitioning is a very important mechanism for plants to cope with the availability of resources in the environment (Bloom, 1985; Bonifas and Lindquist, 2006). Plants distribute more nutrients into shoots to compete for more light in a nutrient-rich environment, whereas in a nutrient-poor environment, more nutrients were distributed into the roots (Tilman, 1985). As reported, after 7-day germination under favourable environment conditions, about two-thirds of nutrients remain in maize seeds (Li et al., 2018). So, maize seeds can supply adequate nutrition for germination. Accordingly, it is logical that during maize seed germination, nutrients might be preferentially distributed to the shoots. And, shoot biomass of the seedlings can indicate the nutrient supply ability of seeds, that is, the seed vigour level. In the present study, our results were consistent with this inference, the differences in SDWVI showing closer correlation with the differences in the average $\mathrm{Ca}^{2+}$ influx rate than PDWVI and RDWVI (Figure 4).

NMT is an ultrasensitive technology with high spatial and temporal resolution (McLamore and Porterfield, 2011). Thus, an appropriate selection of the materials and positions for detection is critical for obtaining stable and reliable data. In this study, we first used the entire maize seeds for detection and found that the $\mathrm{Ca}^{2+}$ flux rate obtained had low stability and low values. Next, we used the intact maize embryo as materials, and the $\mathrm{Ca}^{2+}$ flux rate detected showed significantly increased stability and higher values. In maize seeds, the embryo is living tissue, but the endosperm and the compact pericarp and testa are dead tissues (Larkins, 2017). Only the living tissue responds to stimulation from the external environment; and the influence of the dead tissues may be why the $\mathrm{Ca}^{2+}$ flux rate measured in the intact seeds showed such low stability. When Li et al. (2014) measured the flux rate of $\mathrm{O}_{2}$ and $\mathrm{H}_{2} \mathrm{O}_{2}$ in $C$. korshinskii seeds using NMT, non-coated seeds were used as materials, similar to the method used in this study.

\section{Conclusion}

In the present study, with maize seeds with different vigour levels of four genotypes as materials, we found that there was a significant, positive linear correlation between the SDWVI and $\mathrm{Ca}^{2+}$ flux rate into the embryo. The results demonstrated that the $\mathrm{Ca}^{2+}$ influx rate can be used to evaluate the vigour levels of maize seeds. Because the roles of $\mathrm{Ca}^{2+}$ in promoting seed germination and increasing stress resistance of seedling are common in different plant species (see introduction and discussion sections), $\mathrm{Ca}^{2+}$ influx rate is expected to be valuable in testing the seed vigour levels of various plant species.

\section{Conflicts of interest}

The authors declare that they have no conflicts of interest.

\section{Compliance with Ethical Standards}

This article does not contain any studies with human participants or animals performed by any of the authors.

\section{Funding}

This work was supported by the National Key Research and Development Program of China (2018YFD0100901), and Shandong Agricultural Elite Variety Project (2019LZGC002).

\section{References}

Bello, P. and Bradford K.J., 2016. Single-seed oxygen consumption measurements and population-based threshold models link respiration and germination rates under diverse conditions. Seed Science Research 26: 199-221. http://doi.org/10.1017/ S0960258516000179

Bickerton, P.D. and Pittman, J.K., 2012. Calcium signalling in plants. In: eLS. John Wiley \& Sons, Chichester. http://doi. org/10.1002/9780470015902.a0023722

Bloom, A., 1985. Resource limitation in plants-An economic analogy. Annual Review of Ecology, Evolution, and Systematics 16: 363-392. https://doi.org/10.1146/annurev.ecolsys.16.1.363

Bonifas, K.D. and Lindquist, J.L., 2006. Predicting biomass partitioning to root versus shoot in corn and velvet leaf (Abutilon theophrasti). Weed Science 54: 133-137. https://doi.org/10.1614/ WS-05-079R1.1

Cheng, Y., Zhang, X., Sun, T., Tian, Q. and Zhang, W.H., 2018. Glutamate receptor homolog3.4 is involved in regulation of seed germination under salt stress in Arabidopsis. Plant and Cell Physiology 59: 978-988. http://doi.org/10.1093/pcp/pcy034.

Domínguez, F. and Cejudo F.J., 2014. Programmed cell death (PCD): an essential process of cereal seed development and germination. Frontiers in plant science 5: 366. http://doi.org/10.3389/ fpls.2014.00366

Farooq, M., Aziz, T., Basra, S.M.A., Wahid, A., Khaliq, A. and Cheema, M.A., 2008. Exploring the role of calcium to improve chilling tolerance in hybrid maize. Journal of Agronomy and Crop Science 194(5): 350-359. http://doi.org/10.1111/j.1439-037X.2008.00322.x

Finch-Savage, W. and Bassel, G., 2016. Seed vigour and crop establishment: extending performance beyond adaptation. Journal of Experimental Botany 67(3): 567-591. http://doi.org/10.1093/jxb/ erv 490 
Hampton, J.M. and Tekrony, D.M., 1995. Handbook of vigour test methods, $3^{\text {rd }}$ edition. International Seed Testing Association, Zürich, Switzerland.

Han, Z., Ku, L., Zhang, Z., Zhang, J., Guo, S., Liu, H., Zhao, R., Ren, Z., Zhang, L., Su, H., Dong, L. and Chen, Y., 2014. QTLs for seed vigor related traits identified in maize seeds germinated under artificial aging conditions. PLoS One 9: e92535. http://doi. org/10.1371/journal.pone.0092535

ISTA, 2014. International rules for seed testing. International Seed Testing Association, Bassersdorf, Switzerland.

Jing, X., Cai, C., Fan, S., Wang, L. and Zeng, X., 2019. Spatial and temporal calcium signaling and its physiological effects in moso bamboo under drought stress. Forests 10(3): 224. http://doi. org/10.3390/f10030224

Kaneko, M., Itoh, H., Ueguchi-Tanaka, M., Ashikari, M. and Matsuoka, M., 2002. The $\alpha$-amylase induction in endosperm during rice seed germination is caused by gibberellin synthesized in epithelium. Plant Physiology 128: 264-270. http://doi. org/10.2307/4280405

Khan, S., Verma, G. and Sharma, S., 2010. A novel $\mathrm{Ca}^{2+}$-activated protease from germinating Vigna radiata seeds and its role in storage protein mobilization. Journal of Plant Physiology. 167(11): 855-861. http://doi.org/10.1016/j.jplph.2010.01.010

Li, J., Wang, Y., Pritchard, H.W. and Wang, X., 2014. The fluxes of $\mathrm{H}_{2} \mathrm{O}_{2}$ and $\mathrm{O}_{2}$ can be used to evaluate seed germination and vigor of Caragana korshinskii. Planta 239(6): 1363-1373. http://doi. org/10.1007/s00425-014-2049-7

Li, Y., Qu, H., Zhu, P., Su, K., Zhang, C., 2018. Comparative proteomics reveals the mechanisms underlying variations in seed vigor based on maize (Zea mays L.) ear positions. Plant Molecular Biology Reporter 36: 738-749. https://doi.org/10.1007/ s11105-018-1115-x

Li, Z.G., Ye, X.Y. and Qiu, X.M., 2019. Glutamate signaling enhances the heat tolerance of maize seedlings by plant glutamate receptor-like channels-mediated calcium signaling. Protoplasma 256: 1165-1169. https://doi.org/10.1007/ s00709-019-01351-9
Mclamore, E.S. and Porterfield, D.M., 2011. Non-invasive tools for measuring metabolism and biophysical analyte transport: self-referencing physiological sensing. Chemical Society Reviews 40(11): 5308-5320. https://doi.org/10.1039/c0cs00173b

Midhat, U., Ting, M.K.Y., Teresinski, H.J. and Snedden, W.A., 2018. The calmodulin-like protein, CML39, is involved in regulating seed development, germination, and fruit development in Aarabidopsis. Plant Molecular Biology 96: 375-392. https://doi. org/10.1007/s11103-018-0703-3

Salahshoor, F. and Kazemi, F., 2016. Effect of calcium on reducing salt stress in seed germination and early growth stage of Festuca ovina L. Plant Soil and Environment 62: 460-466. https://doi. org/10.17221/319/2016-PSE

Sanders, D., Brownlee, C. and Harper, J.F., 1999. Communicating with calcium. Plant Cell 11(4):691-704.

Singh, K.L., Mukherjee, A. and Kar, R.K., 2017. Early axis growth during seed germination is gravitropic and mediated by ROS and calcium. Journal of Plant Physiology 216: 181-187. https://doi. org/10.1016/j.jplph.2017.07.001

Stael, S., Wurzinger, B., Mair, A., Mehlmer, N., Vothknecht, U.C. and Teige, M., 2012. Plant organellar calcium signalling: an emerging field. Journal of Experimental Botany 63(4): 1525-1542. https:// doi.org/10.1093/jxb/err394.

Tilman, D., 1985. The resource-ratio hypothesis of plant succession. American Naturalist 125: 827-852. https://doi.org/10.1086/284382

Verma, G., Khan, S., Agarwal, S.K. and Sharma, S., 2019. Role of apoplastic calcium during germination and initial stages of seedling establishment in Vigna radiata seeds. Journal of Plant Physiology 236: 66-73. https://doi.org/10.1016/j.jplph.2019.02.009

Xin, X., Wan, Y., Wang, W., Yin, G., Mclamore, E.S. and Lu, X., 2013. A real-time, non-invasive, micro-optrode technique for detecting seed viability by using oxygen influx. Scientific Reports 3(1): 3057. https://doi.org/10.1038/srep03057

Zehra, A., Gul, B., Ansari, R. and Khan, M.A., 2012. Role of calcium in alleviating effect of salinity on germination of Phragmites karka seeds. South African Journal of Botany 78: 122-128. https://doi. org/10.1016/j.sajb.2011.05.016 